\title{
Nivolumab-Associated Acute Demyelinating Encephalitis: A Case Report and Literature Review
}

\author{
Zubair Zafar, MD; Carrie Vogler, PharmD, BCPS; Tamer Hudali, MD, FACP; \\ and Mukul Bhattarai, MD, FACP
}

\begin{abstract}
Nivolumab is a checkpoint inhibiting immunotherapeutic agent prescribed for the treatment of resistant cancers. Many immune-related adverse effects including neurological effects have been described, but central nervous system (CNS) toxicities are rarely reported. We present a 59-year-old Caucasian woman with a history of treatment-resistant, progressive, laryngeal squamous cell carcinoma. She received nivolumab and presented with gradual weakness, confusion, and progressive dyspnea. Magnetic resonance imaging of the head showed multifocal cerebral demyelination, primarily involving the parietal lobe. The diagnosis of acute demyelinating encephalitis was made. She improved dramatically after stopping nivolumab and receiving treatment with high-dose intravenous steroid and immunoglobin therapy. We conclude, from this case and literature review, that immune checkpoint inhibitor treatment requires more investigation to determine if autoimmune encephalitis with demyelination can occur as a severe form of immune-related adverse events. CNS toxicity appears to be reversible with prompt cessation of immunotherapy followed by treatment with high doses of steroid with or without intravenous immunoglobulin therapy.
\end{abstract}

Keywords: Anti PD- I; Checkpoint inhibitor; Demyelination; Nivolumab

$\mathrm{T}$ he advent of immunotherapy is one of the most recent and important achievements in the treatment of cancer. Nivolumab is one of the first immune checkpoint inhibitors that targets programmed death receptor-1 (PD-1). The US Food and Drug Administration (FDA) approved nivolumab for therapeutic benefit in non-small cell lung cancer, renal cancer, and melanoma. ${ }^{1}$ Recently, nivolumab received accelerated approval for the treatment of hepatocellular carcinoma and recurrent or metastatic head and neck cancer., ${ }^{2,3}$ Being a relatively new treatment modality, limited data exist on its potential toxicities. Neurotoxicity is not a common adverse effect of PD-1 inhibitors, although anecdotal data has reported an association between PD-1 inhibition therapy and neurotoxicity. ${ }^{4-9}$ Many immune-related adverse effects, including neurological effects, have been reported, ${ }^{7}$ but central nervous system (CNS) toxicities are rarely described..$^{9,10} \mathrm{We}$ describe a case of nivolumab therapy in a patient that developed acute demyelinating encephalitis,

Corresponding Author: Mukul Bhattarai, MD, FACP, 80I N Rutledge St, Springfield, IL 62702 USA, Email: drmukulbhattarai@gmail.com which may add to the growing body of literature of nivolumab adverse effects due to immune checkpoint blockade. Further studies are warranted to confirm any causal association between immune checkpoint blockade and autoimmune encephalitis.

\section{Case Presentation}

A 59-year-old Caucasian woman presented with gradual weakness, altered mental status, and progressive dyspnea requiring intubation for airway protection. Her past medical history was significant for laryngeal squamous cell carcinoma for which she received resection surgery and completed radiation therapy 5 years prior. She was recently diagnosed with progressive recurrent laryngeal cancer with metastatic spread to the lungs. Carboplatin and paclitaxel were started as initial chemotherapy. The therapy was discontinued after two cycles because of severe pancytopenia and recurrent pneumonias. Nivolumab was started as palliative

Received: February 18, 2018

Ist Revision: November 9, 2019

2nd Revision: February 15, 2019

Accepted: March 6, 2019

doi: $10.3121 / \mathrm{cmr} .2019 .1417$ 
immunotherapy 2 weeks prior to her admission, with a dose of $3 \mathrm{mg} / \mathrm{kg}$ planned to repeat every 2 weeks for palliative measures. She developed nausea and reported several falls, which led to her hospital admission and precluded her from getting a second dose of nivolumab. The diagnosis of sepsis secondary to pneumonia was made, as suggested by respiratory symptoms and the presence of new bilateral infiltrates on chest radiography. She started on broad spectrum antibiotic therapy and began full ventilator support. Aggressive measures in the intensive care unit improved her pneumonia and hemodynamic status, but she remained obtunded. Computerized tomography scan did not reveal any acute pathology. Initial laboratory testing showed leukocytosis and reactive lymphocytosis. Her complete metabolic panel was essentially unremarkable: aspartate aminotransferase, alkaline phosphatase, and total bilirubin were normal, and her creatinine was $0.7 \mathrm{mg} / \mathrm{dL}$ reflecting an estimated glomerular filtration rate of $100 \mathrm{~mL} / \mathrm{min} / 1.73 \mathrm{~m}^{2}$. Electroencephalogram demonstrated the presence of diffuse generalized slowing with practically no significant reactivity to external stimuli. Lumbar puncture was performed, and cerebrospinal fluid showed elevated white blood cell count of $74 / \mathrm{mm}^{3}$ with $26 \%$ neutrophils, 41\% lymphocytes, $23 \%$ monocytes, elevated protein, and the presence of oligoclonal bands, with no malignant cells. All tests were negative for infectious pathogens including polymerase chain reaction for cytomegalovirus, varicella zoster virus and herpes simplex virus, as well as tests for acid-fast bacilli, cryptococcal antigen, Lyme antigen, human immunodeficiency virus, venereal disease, and enterovirus.

Subsequent imaging with brain magnetic resonance imaging (MRI) showed multiple hyperintense T2 flair signal white matter lesions primarily in the parietal lobes but also involving the posterior frontal lobes, corpus callosum, and right brachium pontis (Figure 1A). None of these lesions were enhanced following contrast administration (Figure 1B). No restricted diffusion was present. No significant mass effect or midline shift was identified. These findings were suggestive of an acute demyelinating encephalomyelitis, and she was thought to have immunotherapy-induced demyelination. The diagnosis was assumed after the temporal association with the recent initiation of nivolumab and after excluding the other causes. She was treated with methylprednisolone 1 gram intravenously daily for 5 days starting on day 5 of admission, followed by intravenous immunoglobulin therapy (IVIg) of 20 grams daily for 4 days. Gradual improvement of motor function, such as moving extremities in response to pain, was noticed on day 12 of therapy. Deep tendon reflexes were normal except for upward plantar reflex on the left side. She continued to recover motor function and was able to work with physical therapy. She was noted to have receptive and expressive aphasia, which remained until her discharge to rehabilitation. Follow-up MRI in one month showed interval improvement of demyelination (Figure 1C).

\section{Discussion}

We present a rare case of acute demyelinating encephalitis in a 59-year-old Caucasian woman who was on a checkpoint inhibiting immunotherapeutic agent (nivolumab) to treat progressive laryngeal squamous cell carcinoma. Nivolumab has revolutionized the treatment of metastatic cancers and several chemotherapy resistant cancers. This immune checkpoint blockade increases antitumor immunity by blocking intrinsic down-regulators of immunity, such as cytotoxic T-lymphocyte antigen 4 (CTLA-4) and programmed cell death 1 (PD-1) or its ligand, programmed cell death ligand 1 (PD-L1). ${ }^{11}$ PD-L1 is highly selectively expressed on tumor infiltrating lymphocytes from many tumors. The drug ultimately disrupts the negative signal that regulates T-cell activation and proliferation, which plays a key role in tumor evasion from host immunity, resulting in effective antineoplastic activity. ${ }^{8}$ The phenomenon is also known as immune checkpoint inhibition. Several checkpoint inhibitors, including ipilimumab, dacarbazine, and pembrolizumab, are being used in current clinical practice in combination or as monotherapy. Meanwhile, such checkpoint inhibition can cause a unique spectrum of side effects known as immune-related adverse events. The exact mechanism of such adverse reaction is not known, but the hypothesis is focused around the immunologic homeostasis in the setting of immune checkpoint exposure. ${ }^{11}$ Acute encephalopathy from demyelination is rarely discussed.,.$^{9,12}$

A meta-analysis published in 2017 discussed the common neurotoxic adverse effects of nivolumab, which included fatigue, headache, dysgeusia (distortion of the sense of taste), vertigo, paresthesia, anxiety or malaise, and peripheral neuropathy. The study concluded that nivolumab treatment is associated with decreased risk of paresthesia and peripheral neuropathy when compared to the control group. ${ }^{13}$ In contrast to this report, we presented a case of acute demyelinating encephalitis, which can be a severe form of immune-related adverse events, that occurred after the initiation of nivolumab. Our patient presented with altered mental status (AMS) and had abnormal MRI brain findings. We reasonably excluded other causes of AMS, thereby meeting the diagnostic criteria for probable autoimmune encephalitis (AIE) proposed by an international working group, ${ }^{14}$ and hypothesized the checkpoint inhibitor treatment nivolumab to be the most likely cause.

Tumor-induced paraneoplastic neurologic disorders are great mimickers of autoimmune encephalitis. Paraneoplastic neurologic disorders are usually subacute and progressive and commonly detected months to years before diagnosis of a tumor. ${ }^{5}$ Imaging of the brain may not consistently show any abnormal findings, but our case revealed characteristic demyelination primarily in the parietal lobe. Checking the N-methyl-D-aspartate receptors (NMDAR) antibodies in the cerebrospinal fluid may be useful, but it is not required to make a diagnosis of CNS toxicity related to autoimmune process. ${ }^{5}$ Only one case presented by Williams et $\mathrm{al}^{5}$ had cerebrospinal fluid that tested positive for NMDAR antibody, but the patient had a history of melanoma that could cause the 

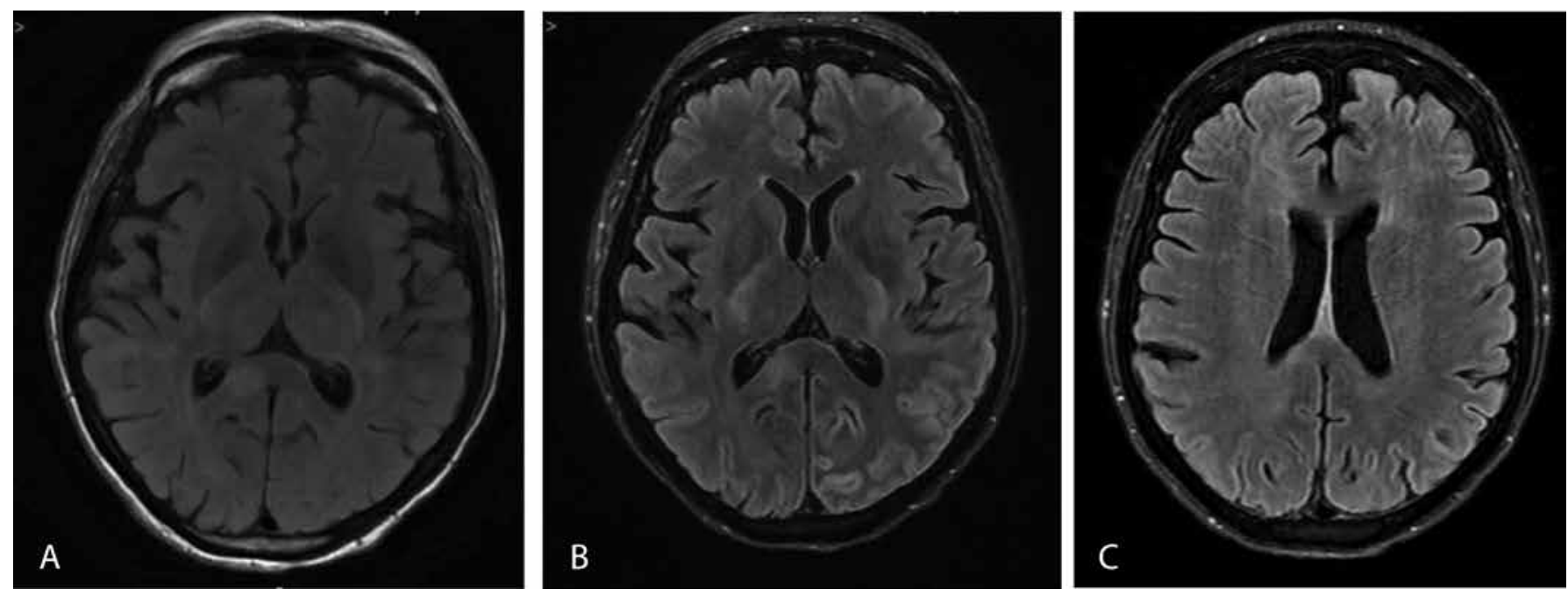

Figure 1. Brain MRI (A) without contrast and (B) with contrast enhancement showing multiple hyperintense T2 flair signal white matter lesions primarily in the parietal lobes but also involving the posterior frontal lobes, corpus callosum, and right brachium pontis. (C) Contrast-enhanced brain MRI at 1-month follow up.

expression of NMDAR on melanocytes. Moreover, patients with autoimmune encephalitis, unlike those with paraneoplastic neurologic disorders, show significant clinical improvement after treatment of steroids with or without IV immunoglobulin. The radiographic appearance of the demyelinating lesions, diffusion restriction, and enhancement patterns that we found in our case did not have the typical characteristics or clinical features of multiple sclerosis.

A Medline and Google Scholar search with "nivolumab" or "immunotherapy" as a single term or combined with "encephalopathy" or "adverse reactions" revealed five cases of nivolumab directly associated with CNS toxicity, including spinal cord demyelination. As a monotherapy, nivolumab is attributed to causing akathisia and chronic inflammatory demyelinating polyneuropathy as CNS side effects., ${ }^{4,6}$

Table 1 describes all published cases where nivolumab (with or without use of other checkpoint inhibitors) caused different types of CNS side effects, not limited to AIE. We believe that ours is the second case in the literature where nivolumab as monotherapy was given, and the patient experienced AIE as a part of severe immune-related adverse events. ${ }^{9}$ Schneider et $\mathrm{al}^{9}$ first reported acute AIE in a patient taking nivolumab for non-small cell lung cancer. Within 24 hours after administration of methylprednisolone $(1.33 \mathrm{mg} / \mathrm{kg}$ body weight), the patient's Glasgow Coma Score improved from 7 at the time of presentation to $15 .{ }^{9}$ However, MRI did not show characteristic demyelination as it did in our case. The diagnosis was hypothesized as probable AIE based on diagnostic criteria set by an international working group, similar to our case. ${ }^{14}$

Two cases of AIEs were reported by Williams et $\mathrm{al}^{5}$ in patients taking combination nivolumab $1 \mathrm{mg} / \mathrm{kg}$ and ipilimumab $3 \mathrm{mg} / \mathrm{kg}$. Withdrawal of immune checkpoint inhibitors and initiation of intravenous methylprednisolone sodium succinate (equivalent to $1000 \mathrm{mg}$ of methylprednisolone) for 5 days, $0.4 \mathrm{mg} / \mathrm{kg} /$ day of intravenous immunoglobulin for 5 days, and two doses of rituximab (1000 $\mathrm{mg})$ in one patient, and only oral prednisone $(60 \mathrm{mg} /$ day $)$ in the other, resulted in dramatic improvement of neurologic symptoms. ${ }^{5}$ Similarly, Maurice et $\mathrm{al}^{10}$ reported a case of AIE with demyelination findings in MRI, like in our case, but the patient was treated for malignant melanoma and had received ipilimumab prior to nivolumab therapy. The patient initially responded very well with IVIG and steroid, but unfortunately died later because of progressive AIE. The neurological side effects of immune checkpoint inhibitors can be severe and occur frequently with the combined use of two immune checkpoint inhibitors. ${ }^{15}$ Data obtained from all cases reported on nivolumab induced CNS toxicities correlates with the findings by Sznol et al, ${ }^{7}$ who demonstrated that side effects can occur more frequently with combination of checkpoint inhibitors, such as nivolumab plus ipilimumab, and can occur earlier than historical experience with either agent alone. ${ }^{10}$ Nivolumab has indications from the National Cancer Institute to be used during or after platinum chemotherapy in several cancers, and effects of worsening disease or previous drug therapy could contribute to neurotoxicity. ${ }^{16}$ Currently, there is no tool to predict who will develop neurotoxicity after receiving a PD-1 inhibitor. ${ }^{17}$ Monitoring laboratory values and clinical parameters can help to recognize signs and symptoms of developing neurotoxicity, but this is after adverse effects have already developed. ${ }^{13}$

Data suggest that CNS side effects are commonly present in malignant melanoma (Table 1). This could be because nivolumab is primarily used in malignant melanoma as first line treatment, and nivolumab use is likely higher in malignant melanoma than in any other cancers. With the recent approval of this agent for treatment in several cancers and increasing use of other checkpoint inhibitors, the incidence of CNS 
Table 1. Review of cases of CNS (including spinal cord) toxicity secondary to nivolumab as monotherapy and also in association with other check point inhibitors

\begin{tabular}{|c|c|c|c|c|c|}
\hline $\begin{array}{l}\text { Case/reference/ } \\
\text { year }\end{array}$ & $\begin{array}{l}\text { Age/sex/type of } \\
\text { neurotoxicity CT/ } \\
\text { MRI Role in } \\
\text { diagnosis }\end{array}$ & $\begin{array}{l}\text { Indication for } \\
\text { nivolumab }\end{array}$ & $\begin{array}{l}\text { Drug and dose } \\
\text { inducing, onset of } \\
\text { symptoms }\end{array}$ & Treatment provided & Outcome \\
\hline $\begin{array}{l}\text { Schneider et al, } \\
2017^{9}\end{array}$ & $\begin{array}{l}78 / \mathrm{M} ; \\
\text { autoimmune } \\
\text { encephalitis; MRI } \\
\text { brain not } \\
\text { mentioned }\end{array}$ & $\begin{array}{l}\text { non-small cell } \\
\text { lung cancer }\end{array}$ & $\begin{array}{l}\text { nivolumab } 3 \mathrm{mg} / \mathrm{kg} \text { every } \\
2 \text { weeks; symptoms after } \\
28 \text { weeks }\end{array}$ & $\begin{array}{l}\text { methylprednisolone ( } 1.33 \\
\mathrm{mg} / \mathrm{kg}) ; 12 \text { days after the } \\
\text { 14th application of } \\
\text { nivolumab ( } 28 \text { weeks after } \\
\text { the first dose) }\end{array}$ & $\begin{array}{l}\text { improved within } \\
24 \text { hours of } \\
\text { steroid treatment, } \\
\text { GCS back to } 15\end{array}$ \\
\hline $\begin{array}{l}\text { Williams et al, } \\
2016,{ }^{5} \text { Case } 1\end{array}$ & $\begin{array}{l}\text { mid-60s; } \\
\text { autoimmune } \\
\text { encephalitis; MRI } \\
\text { brain abnormal } \\
\text { (demyelination) }\end{array}$ & $\begin{array}{l}\text { metastatic small } \\
\text { cell lung cancer }\end{array}$ & $\begin{array}{l}\text { nivolumab } 1 \mathrm{mg} / \mathrm{kg} \text { and } \\
\text { ipilimumab } 3 \mathrm{mg} / \mathrm{kg} \text {; } \\
\text { symptoms within } 4 \text { days } \\
\text { of the initial doses that } \\
\text { worsened to confusion } \\
\text { and ataxia by week } 4\end{array}$ & $\begin{array}{l}\text { oral prednisone, } 60 \mathrm{mg} / \\
\text { day }\end{array}$ & $\begin{array}{l}\text { returned to } \\
\text { baseline }\end{array}$ \\
\hline $\begin{array}{l}\text { Williams et al, } \\
2016,{ }^{5} \text { Case } 2\end{array}$ & $\begin{array}{l}50 \text { FF; } \\
\text { autoimmune } \\
\text { encephalitis; MRI } \\
\text { brain- abnormal } \\
\text { (demyelination) }\end{array}$ & $\begin{array}{l}\text { metastatic } \\
\text { melanoma }\end{array}$ & $\begin{array}{l}\text { nivolumab } 1 \mathrm{mg} / \mathrm{kg} \text { and } \\
\text { ipilimumab } 3 \mathrm{mg} / \mathrm{kg} \text {; } \\
\text { symptoms started } 1 \text { week } \\
\text { after treatment and } \\
\text { worsened to confusion by } \\
\text { day } 18\end{array}$ & $\begin{array}{l}\text { high dose intravenous } \\
\text { steroid equivalent to } \\
1000 \mathrm{mg} / \text { day of } \\
\text { methylprednisolone for } 5 \\
\text { days, followed by } 0.4 \mathrm{mg} / \\
\mathrm{kg} / \text { day of intravenous } \\
\text { immunoglobulin for } 5 \text { days; } \\
2 \text { doses of intravenous } \\
\text { rituximab, } 1000 \mathrm{mg} \text {. }\end{array}$ & $\begin{array}{l}\text { gradual } \\
\text { improvement in } \\
\text { mental status for } \\
4 \text { weeks; score } \\
\text { Montreal } \\
\text { Cognitive } \\
\text { Assessment at } 6 \\
\text { months - } 28 \text { of } 30 \\
\text { (normal, } \geq 26 \text { ), } \\
\text { otherwise normal } \\
\text { neurologic } \\
\text { examination } \\
\text { results }\end{array}$ \\
\hline $\begin{array}{l}\text { Maurice et al, } \\
2015^{10}\end{array}$ & $\begin{array}{l}\text { 60/M; subacute } \\
\text { encephalitis; MRI } \\
\text { brain- } \\
\text { demyelination }\end{array}$ & $\begin{array}{l}\text { malignant } \\
\text { melanoma }\end{array}$ & $\begin{array}{l}\text { ipilimumab for } 2 \text { months, } \\
\text { then nivolumab } 3 \mathrm{mg} / \mathrm{kg} \\
\text { every } 2 \text { weeks; symptoms } \\
\text { within two days after the } \\
\text { fourth cycle of nivolumab }\end{array}$ & $\begin{array}{l}\text { high-dose } \\
\text { methylprednisolone } \\
\text { intravenously }(1 \mathrm{~g} \text { per day) } \\
\text { for } 5 \text { days followed by } \\
\text { intravenous immune } \\
\text { globulin (IVIG, } 2 \mathrm{~g} / \mathrm{kg} \text { ) over } \\
5 \text { days }\end{array}$ & $\begin{array}{l}\text { initial significant } \\
\text { improvement; } \\
\text { relapsed and died } \\
\text { in 5months }\end{array}$ \\
\hline $\begin{array}{l}\text { Tanaka et al, } \\
2016^{6}\end{array}$ & $\begin{array}{l}\text { 85/M; CIDP; } \\
\text { paresthesia, } \\
\text { sensory loss, } \\
\text { decrease visual } \\
\text { acuity; MRI spine- } \\
\text { abnormal } \\
\text { (demyelination) }\end{array}$ & $\begin{array}{l}\text { malignant } \\
\text { melanoma }\end{array}$ & $\begin{array}{l}\text { nivolumab initiated at a } \\
\text { dose of } 2 \mathrm{mg} / \mathrm{kg} \text { per body } \\
\text { weight, every } 3 \text { weeks; } \\
\text { symptoms two weeks } \\
\text { after the initial dose }\end{array}$ & $\begin{array}{l}\mathrm{IVIg} 400 \mathrm{mg} / \mathrm{kg} / \mathrm{day} \text { for } 5 \\
\text { days, prednisolone } 1 \mathrm{mg} / \\
\mathrm{kg} \text { with gradual tapering. }\end{array}$ & $\begin{array}{l}\text { improved motor } \\
\text { function }\end{array}$ \\
\hline Abe et al, $2016^{4}$ & $\begin{array}{l}\text { 58/M; akathisia; } \\
\text { MRI brain- } \\
\text { unremarkable }\end{array}$ & $\begin{array}{l}\text { advanced lung } \\
\text { adenocarcinoma }\end{array}$ & $\begin{array}{l}\text { nivolumab- }(150 \mathrm{mg} / \\
\text { body); symptoms } 4 \text { days } \\
\text { after initial dose of } \\
\text { nivolumab }\end{array}$ & $\begin{array}{l}\text { prednisolone } 50 \mathrm{mg} \text { for } \\
\text { possible immune-related } \\
\text { encephalitis; biperiden, } \\
\text { alprazolam, and diazepam } \\
\text { were used to treat the } \\
\text { akathisia }\end{array}$ & not mentioned \\
\hline $\begin{array}{l}\text { Zafar et al, } 2017 \\
\text { (our case) }\end{array}$ & $\begin{array}{l}\text { 59/F; acute } \\
\text { demyelinating } \\
\text { encephalitis; MRI } \\
\text { brain-abnormal } \\
\text { (demyelination) }\end{array}$ & $\begin{array}{l}\text { progressive } \\
\text { laryngeal cancer }\end{array}$ & $\begin{array}{l}\text { nivolumab } 3 \mathrm{mg} / \mathrm{kg} \\
\text { symptoms started } 12 \\
\text { days after initial dose }\end{array}$ & $\begin{array}{l}\text { methylprednisolone } 1 \mathrm{~g} \mathrm{IV} \\
\text { daily for } 5 \text { days starting on } \\
\text { day } 5 \text { of admission } \\
\text { followed by IVIg } 20 \mathrm{gm} \\
\text { daily for } 4 \text { days }\end{array}$ & $\begin{array}{l}\text { improved, } \\
\text { aphasia persisted } \\
\text { at the time of } \\
\text { discharge to } \\
\text { rehab }\end{array}$ \\
\hline
\end{tabular}

Abbreviations: CNS, Central Nervous system; CT, computed tomography; MRI, magnetic resonance imaging; GCS, Glasgow Coma Scale; CIDP, chronic inflammatory demyelinating polyradiculoneuropathy; IVIG, intravenous immunoglobulin; 
toxicities may increase in the future. Nevertheless, in all these cases of neurological complications, cessation of the culprit drug and immediate use of steroids and immunoglobulin has led to significant neurological recovery.

The heterogeneous neurologic complications of other checkpoint inhibitors have been reported. Ipilimumab, which targets CTLA-4, has been associated with Guillain-Barré syndrome, multifocal radiculoneuropathy, and chronic inflammatory demyelinating polyneuropathy as immunerelated adverse events $\mathrm{s} .{ }^{10}$ Similarly, pembrolizumab (also named lambrolizumab), which works like nivolumab by blocking immune regulatory signaling of the PD-1 receptor, also has been reported to cause CNS toxicity with MRI findings, like our case. ${ }^{13}$ Immune-related adverse events are significantly less frequent with the anti-PD-1 antibodies compared with ipilimumab. ${ }^{18}$

The timing of onset of neurological symptoms after administration of nivolumab is important. Knowing this would help in early suspicion of immune-related adverse events involving the CNS. Most patients had onset of symptoms 4 days after administration of nivolumab, and symptoms became progressively worse within 2 weeks, except in one case where symptoms developed after 28 weeks of anti-PD-1 monotherapy. ${ }^{9}$

To conclude, the use of checkpoint inhibitors as immunotherapy has accelerated because of its positive outlook in cancer survival. Autoimmune encephalitis does not present with a well-defined syndrome, but it should be evaluated in any patient who develops altered mental status after the use of immunotherapy like nivolumab. Our case and the reviewed literature emphasize the importance of clinicians and researchers recognizing the early presentation of AIE secondary to checkpoint inhibitors and beginning early steroid treatment for better outcome and unnecessary investigation. Indeed, more data is needed to determine if a causal relationship exists between nivolumab and AIE due to the severity of the neurotoxicity adverse events that have been previously reported.

\section{References}

1. U.S. Food \& Drug Administration. Drugs@FDA: FDA Approved Drug Products. Biologic License Application (BLA): 125527. Available at: https://www.accessdata.fda. gov/scripts/cder/daf/index.cfm?event=overview. process\&applno=125527. Accessed December 17, 2017.

2. U.S. Food \& Drug Administration. Drugs. FDA grants accelerated approval to nivolumab for HCC previously treated with sorafenib. U.S Food \& Drug Administration web site. Available at: https://www.fda.gov/Drugs/ InformationOnDrugs/ApprovedDrugs/ucm577166.htm. Accessed February 1, 2018.

3. U.S. Food \& Drug Administration. Drugs. Nivolumab for SCCHN. Available at: https://www.fda.gov/Drugs/ InformationOnDrugs/ApprovedDrugs/ucm528920.htm. Accessed February 13, 2018.
4. Abe J, Sato T, Tanaka R, Okazaki T, Takahashi S. NivolumabInduced Severe Akathisia in an Advanced Lung Cancer Patient. Am J Case Rep. 2016;17:880-882.

5. Williams TJ, Benavides DR, Patrice KA, et al. Association of Autoimmune Encephalitis With Combined Immune Checkpoint Inhibitor Treatment for Metastatic Cancer. JAMA Neurol. 2016;73:928-933.

6. Tanaka R, Maruyama H, Tomidokoro Y, et al. Nivolumabinduced chronic inflammatory demyelinating polyradiculoneuropathy mimicking rapid-onset Guillain-Barré syndrome: a case report. Jpn J Clin Oncol. 2016;46:875-878.

7. Sznol M, Ferrucci PF, Hogg D, et al. Pooled Analysis Safety Profile of Nivolumab and Ipilimumab Combination Therapy in Patients With Advanced Melanoma. J Clin Oncol. 2017;35:3815-3822.

8. Robert C, Long GV, Brady B, et al. Nivolumab in previously untreated melanoma without BRAF mutation. N Engl J Med. 2014;372:320-30.

9. Schneider S, Potthast S, Komminoth P, Schwegler G, Böhm S. PD-1 Checkpoint Inhibitor Associated Autoimmune Encephalitis. Case Rep Oncol. 2017;10:473-478.

10. Maurice C, Schneider R, Kiehl T, et al. Subacute CNS Demyelination after Treatment with nivolumab for Melanoma. Cancer Immunol Res. 2015;3:1299-1302.

11. Postow MA, Sidlow R, Hellmann MD. Immune-Related Adverse Events Associated with Immune Checkpoint Blockade. N Engl J Med. 2018;378:158-168.

12. Kumar V, Chaudhary N, Garg M, Floudas CS, Soni P, Chandra AB. Current Diagnosis and Management of Immune Related Adverse Events (irAEs) Induced by Immune Checkpoint Inhibitor Therapy. Front Pharmacol. 2017;8:49.

13. Kong X, Kong Y. Evidence from a meta-analysis : is nivolumab neurotoxic in cancer patients? Onco Targets Ther. 2017; 10:1335-1344

14. Graus F, Titulaer MJ, Balu R, et al. A clinical approach to diagnosis of autoimmune encephalitis. Lancet Neurol. 2016;15:391-404.

15. Cuzzubbo A, Javeri F, Tissier M, et al. Neurological adverse events associated with immune checkpoint inhibitors: Review of the literature. Eur J Cancer. 2017;73:1-8.

16. NIH National Cancer Institute. Non-Small Cell Lung Cancer Treatment (PDQ ${ }^{\circledR)}$-Health Professional Version. Treatment Option Overview for NSCLC. Available at: https://www. cancer.gov/types/lung/hp/non-small-cell-lung-treatmentpdq\#section/_514. Accessed January 18, 2018.

17. Mandel JJ, Olar A, Aldape KD, Tremont-Lukats IW. Lambrolizumab induced central nervous system (CNS) toxicity. J Neurol Sci. 2014;344:229-231. doi: 10.1016/j. jns.2014.06.023

18. Weber JS, Hodi FS, Wolchok JD, et al. Safety Profile of nivolumab Monotherapy: A Pooled Analysis of Patients With Advanced Melanoma. J Clin Oncol. 2017;35(7):785-792. doi: 10.1200/JCO.2015.66.1389.

\section{Author Affiliations}

Zubair Zafar, MD; * Carrie Vogler, PharmD, BCPS; * $\dagger$ Tamer Hudali, MD, FACP; * and Mukul Bhattarai, MD, $F A C P *$
*Department of Internal Medicine, Southern Illinois
University, Springfield, IL.
†Department of Pharmacy Practice, Southern Illinois
University Edwardsville School of Pharmacy, Edwardsville,
IL 